\title{
Risk Factors in Development of Early Childhood Caries in 12-18-month-old Indian Children: A Prospective Study
}

\author{
Puneeth Wadhwa ${ }^{1}$, Ashima Goyal ${ }^{2}$, Krishan Gauba ${ }^{3}$, Harpinder Singh Chawla ${ }^{4}$, Sanjeev Kumar Singh ${ }^{5}$
}

\begin{abstract}
Aims and objectives: To assess the risk factors in the development of early childhood caries (ECC) in 12-18-month-old and also to develop a caries prediction model for the preschool children of Chandigarh and neighboring areas.

Materials and methods: Involving 100 children (12-18 months of age) were initially evaluated for various risk factors viz. maternal history, infant feeding pattern, oral hygiene measures, levels of mutans streptococci, developmental defects of enamel, caries activity, and past caries experience. The children were then followed longitudinally for 18 months to investigate the development of ECC.

Results: At 18 months, 95 children were available for reexamination, and after bivariate correlation analysis; it was found that approximately 11 variables showed a significant difference between children with and without caries. Logistic regression was also carried out to test the strength of correlation which showed mutans streptococci levels, the history of bottle feeding at night, and the presence of enamel hypoplasia to play a highly significant role in the development of ECC.

Conclusion: Recognition of risk factors for ECC and their control and prevention will enable pediatric dentists to improve the oral health of young children.

Keywords: Child, Cohort studies, Deciduous teeth, Dental caries, Oral health, Pediatric dentistry, Preschool, Risk assessment, Risk factors.

Journal of Postgraduate Medicine, Education and Research (2022): 10.5005/jp-journals-10028-1559
\end{abstract}

\section{INTRODUCTION}

Despite the improvement in the oral health of children in recent decades, early childhood caries (ECC), a disease characterized by rampant decay in the primary dentition of infants and young children, continues to pose a serious threat to child welfare. ${ }^{1}$ ECC is a complex, multifactorial infectious disease that begins soon after the eruption of teeth, develops on smooth surfaces, progresses rapidly, and leaves a lasting detrimental impact on the dentition. ${ }^{2}$ The absence of any standardized diagnostic criteria has made the risk assessment of the disease difficult. The term ECC was adopted at a workshop in Bethesda, Maryland conducted by Centers for Disease Control and Prevention on October 18-19, 1997, so as to reflect in a better way the complex etiological factors associated with this disease in young children. ${ }^{3}$ The progress in understanding the etiology, epidemiology, and management of any disease depends on the continuous development of valid and reliable tools that can accurately diagnose the severity of a disease or condition. ${ }^{4} \mathrm{ECC}$ can manifest itself in severe pain, infection, chewing difficulty, stunted growth as well as low self-esteem.

In India, poor awareness about dental caries being a preventable disease is poor and it is widely accepted that primary teeth do not require much care as these would be replaced by permanent teeth. ${ }^{5}$ There has been paucity of studies describing the impact of various child rearing practices on oral health of preschool children. An improvement in understanding the etiology of this condition will lead to better implementation of evidence based oral health programs, hence it has become imperative to evaluate and study various risk factors and their prevalence in Indian population, especially focusing on implementation of preventive measures in those groups or individuals who are at risk of developing ECC. Over the years

\footnotetext{
${ }^{1-5}$ Oral Health Sciences Center, Postgraduate Institute of Medical Education and Research, Chandigarh, India

Corresponding Author: Ashima Goyal, Oral Health Sciences Center, Postgraduate Institute of Medical Education and Research, Chandigarh, India, Phone: +91 1722756831, e-mail: ashimapgi@yahoo.in

How to cite this article: Wadhwa P, Goyal A, Gauba K, et al. Risk Factors in Development of Early Childhood Caries in 12-18-month-old Indian Children: A Prospective Study. J Postgrad Med Edu Res 2022;56(1):7-12.

Source of support: Nil

Conflict of interest: None
}

strategies for managing ECC have increasingly emphasized the concept of risk assessment which is of paramount importance as caries preventive measures are perceived as expensive and there is uneven distribution of the disease in any population. An emerging evidence indicates that a complex interaction of sociodemographic, behavioral, and microbiological factors is responsible for occurrence of dental caries in general and ECC in particular. ${ }^{6}$ However a practical tool for assessing caries risk in infants and young children has been largely lacking and the availability of limited data and absence of well-designed studies evaluating various risk factors for ECC creates additional barrier to the development of a risk assessment predictive model for preschool children of India. All these considerations in part have provided the impetus to conduct the study with an aim to identify risk factors for development of ECC and also to identify new social and behavioral determinants for ECC pattern and severity in young toddlers of Chandigarh, India.

The present study was aimed at evaluating various cariogenic risk factors in the age of 12-18 months to study their possible role in the development of ECC for formulating a caries prediction model 
that could help in assessing high risk caries in children based on the presence of specific risk factors at an early age.

\section{Materials and Methods}

\section{Study Design and Study Population}

This prospective cohort study was conducted over one and a half years in Chandigarh, India. The study population consisted of 100 children aged 12-18 months who were born in the Department of Neonatology of the institution and had lived in Chandigarh till the time of the investigation. This was done to ensure all children are exposed to the same level of fluoride $(0.3 \mathrm{ppm})$ in water. A list of children delivered normally 1-11/2 years back in the institution was obtained from the Department of Neonatology. From the 730 addresses available in the record, 210 households of Chandigarh were shortlisted. Investigators personally visited each of these 210 households, out of which 164 parents could be contacted and were asked to participate in the study. However, after approaching twice, only 117 parents reported with their children to the Department of Pedodontics and Preventive
Dentistry. Finally, a sample of 100 was undertaken as 17 mothers could not consent to the study. The study was conducted in two phases (phase I and II). In phase I, baseline data about various cariogenic risk factors and caries experience was collected at age of 12-18 months. These children were then followed longitudinally and were reevaluated for the development of ECC after a period of one and a half years, that is, at the age of 2.5-3 years (phase II). The materials and methodology of the present study depicted in Flowchart 1.

\section{Ethical Aspects, Consent, and Confidentiality}

Ethical approval for the present study was obtained from the Institutional Ethical Committee. Mothers of the children received both verbal and written information about the purpose of the study. Written informed consent was obtained from the participants before enrollment and confidentiality of the data were ensured to them. Parents were assured dental treatment for their children if any required during the study period. The research has been conducted in full accordance with the World Medical Association Declaration of Helsinki.

Flowchart 1: Flow diagram of methodology

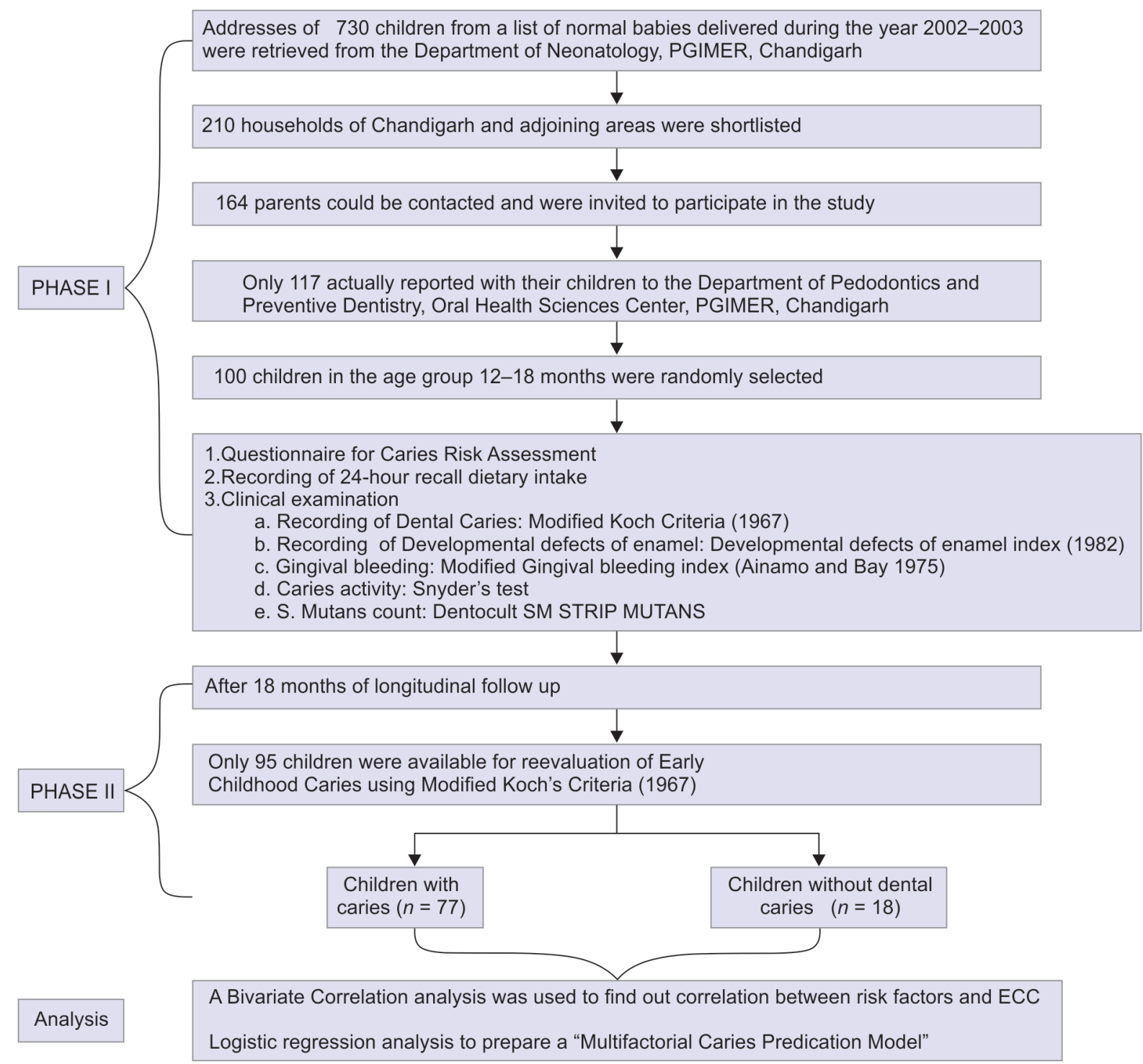




\section{Inclusion and Exclusion Criteria}

Inclusion criteria were normal healthy children aged 12-18 months and mothers willing to participate in the study.

\section{Study Tools and Data Collection}

A specially designed computer compatible questionnaire was designed after reviewing the literature for the present study. It contained closed-ended questions that provided 2-7 options, which were coded. The questionnaire was pretested for validity, reliability, and clarity in the department on 15 mothers of young children. Questions that had ambiguity during the pilot study were revised. Training and calibration of the investigators were done for interviewing mothers and intraoral examination of children. To ensure consistency in an examination, intra- and inter-examiner were done. Clinical training ended when the Kappa value was achieved greater than 0.80 .

\section{Phase I}

Data collection during phase I was done sequentially with a filling of the questionnaire followed by intraoral examination and caries activity test at the end. The questionnaire for the assessment of risk factors for dental caries was filled by trained investigators through individual face to face interviews with the mothers. The 24-hour dietary intake was noted on a proforma and relevant information was also charted. Following risk factors were included in the questionnaire:

\section{Sociodemographics}

Age and gender of the child, the weight of the child at birth, number of siblings, family size, income, Socioeconomic status (SES). SES was assessed using the Modified Kuppuswamy SES Scale. ${ }^{14}$

\section{Mother-related variables}

Mother's education, working status of the mother, supplements taken by mother during pregnancy (multivitamins, folic acid, and calcium supplements). ${ }^{18}$

\section{Children-related variables}

Feeding practices included dietary and nutritional information related questions like whether the child was breast or bottle-fed. Age of initiation of bottle-fed, the pattern of bottle-fed at night, content of bottle feeding, type of pacifiers used (honey pacifier, plain pacifier). The weaning age of the child and sharing of utensils especially spoons were investigated. Oral hygiene practices enquired about child's teeth cleaning frequency, materials used, type of dentifrice used, and whether brushing is self-implemented or performed with mother. Sugar exposure-related dietary habits encompassed frequency and duration of use of sugar-based medication, frequency of consumption of candies, toffees, and sweetened beverages. Other factors like sleep-associated problems, mode of affection shown to children were asked.

For intraoral examination, the child was seated comfortably either on a dental chair or in the mother's lap. Cleaning of the teeth using a cotton pellet was done before recording indices. Dental caries was recorded using modified Koch's criteria (1967), developmental defects of enamel as per Developmental Defects of Enamel index (DDE index) by "FDI Commission on Oral Health, Research and Epidemiology, 1982" and gingival bleeding as per modified Ainamo and Bay index 1975.,8 Modified Koch's criteria is a comprehensive index and record both incipient and manifest caries. The instruments for recording dental caries were carried in individual autoclave pouches, each of which contained one examination set (Hu-friedy probe, mirror, and tweezer). In the majority of the cases, caries was recorded in natural light with the face of the child-directed away from the light source. In some cases, penlight was additionally used for further illumination. The oral examination was done by another investigator who was unaware of the outcome of the mother's interview.

Caries activity test viz. Snyder test was done by the swab method as suggested by Grainges et al. ${ }^{9,10}$ The determination of levels of mutans streptococci (MS) in the saliva was carried out by the "STRIP MUTAN" method of Jensen and Brathal 1989 and this was done using a commercially available Dentocult strip mutan test kit (Orion Diagnostica Finland). The score "0" corresponds to $<104$ of $\mathrm{CFU} / \mathrm{mL}$, "1" to $104-105$ of CFU/mL, "2" to $105-106$ of CFU/mL, and "3" to $>106$ of CFU/mL."

\section{Phase II}

The children included in the study were longitudinally followed for 1.5 years and only 95 children were available for a reevaluation of ECC using the same criteria.

\section{Data management and analysis}

Data were analyzed using SPSS version 22 (IBM Corp., Armonk, NY, USA). Descriptive and inferential statistics were carried out. All the analyses were done on the total number of participants who completed both phases of data collection. The Chi-square test/Fischer exact test was performed to compare statistical differences between the groups. All the variables that were significantly associated in bivariate analysis were included in multiple logistic regression while controlling for latent confounders found in the bivariate analysis. Odds ratios (ORs) with $95 \%$ confidence intervals (Cls) were used to estimate the association. Statistical significance was set at $p<0.05$.

\section{Results}

A total of 95 children out of 100 children ( 59 males and 36 females) were available for follow-up examination (attrition of 5\%) and all the analyses are done as per protocol basis. Both the gender was homogeneously distributed for age ( $p=0.677)$. The majority of the mothers had standard to graduate level of education (67.36) and approximately $82 \%$ were nonworking. For the socioeconomic distribution, the lower-class (51.6\%) was followed by the middle class (48.4\%) and none in the upper class. Around 3/4th (75.8\%) of the children were of average normal weight.

When mothers were assessed according to supplements taken during pregnancy it was found that $89.5 \%$ of the mother took calcium supplements regularly, $69.5 \%$ and $49.5 \%$ of the mothers gave a history of consumption of multivitamins and folic acid, respectively. Only $2.1 \%$ of them did not take any supplements and $91 \%$ of them also reported the intake of iron. Eighty percent of children did not give any history of use of pacifiers and only 14.7 and $5.3 \%$ of the parents admitted giving plain and honey pacifiers, respectively. Mode of affection revealed that $77.9 \%$ of parents gave a history of hugged and cuddled, $89.5 \%$ of the parents kissed their children on the lips. The prevalence of dental caries was $16.84 \%$ at the baseline with the majority of the lesions were limited to the enamel. The follow-up period showed a prevalence of $18.94 \%$. On analyzing of the data, the mean $\mathrm{dmft}$ score at baseline was found to be $0.58 \pm 1.5$ and at final recording $0.68 \pm 1.6$ while the mean dmfs score was found to be $0.87 \pm 2.95$ at baseline and $1.22 \pm 3.2$ at final recording. 
There was no gender predilection for the development of dental caries in the present study (Table 1). Dental caries was significantly associated with age at which bottle feeding started, bottle feeding at night, the pattern of bottle feeding, the content of feeding, oral hygiene measures, assistance during cleaning, frequency of toothpaste, MS levels in the mouth, hypoplasia, and previous caries levels (Table 2).

The variables found significant in bivariate analysis were entered into a logistic regression analysis. Risk factors like history of bottle feeding at night, MS levels, and presence of hypoplasia are significantly associated with the development of ECC (Table 3). The child is likely to develop ECC if there is the presence of any one or more of these generated variables.

\section{Discussion}

This prospective cohort study assessed various risk factors involved in the development of ECC and represents the opportunity to establish a temporal relationship for the risk factors. Of these eleven variables, three were found to be strong predictors of the development of ECC. These three were the use of bottles at night, S. mutans levels, and the presence of enamel hypoplasia.

As the majority of the children were in the middle class (98.94\%), SES as a risk factor for ECC could not be established in the present study. Age has been illustrated to be an important risk factor for ECC by previous studies. ECC has been found to increase with increasing age and is verified by the results of this study. ${ }^{19}$ The age of 12-18 months selected in the present coincides with the eruption of primary teeth and colonization of MS on the teeth. Also, it is a critical time for studying the inhibition and development of dental caries, as during this period children are also exposed to a myriad of cariogenic risk factors. The lack of association between gender and the development of ECC in the present study corroborates with studies in the literature. ${ }^{20,21}$

Systematic reviews and meta-analysis have shown an altogether higher prevalence of ECC in children born preterm when compared to full term. ${ }^{22,23}$ Considering preterm as a potent confounder for ECC, it was avoided in inclusion criteria which could add strength to the study. It was found that children who had milk with sugar and additives and slept with a bottle in their mouth at night had higher chances of ECC in the present study. Sleeping with a bottle in the mouth causes prolonged contact between sugars and bacteria on susceptible teeth. This finding reinforces the literature focusing on sugar and bottle feeding a significant risk factor for ECC. ${ }^{24}$ ECC was more in children who were not cleaning the teeth when compared to counterparts. Similar findings have been reported among 3-5 years children in Nigeria. ${ }^{25}$

American Academy of Pediatric Dentistry (AAPD) in its policy document has recognized that enamel hypoplasia, oral colonization with elevated levels of cariogenic bacteria, especially MS along with poor feeding practices are associated with the development of ECC. The findings of the study are in the same line and ECC was predominant among children with high MS values. ${ }^{26}$

The prevalence of dental caries in every one out of six children shows a wide-reaching implication in terms of dental disease burden. Since the majority of the lesion at the baseline and follow-up were in the enamel and dentin level, it showcases an opportunity for intervention at the primary and secondary level of prevention. Targeting children and mothers at this age might consistently have a positive noteworthy effect on a child's quality of life in the future. The prevalence of ECC (18.94\%) in the present study is however very less when compared to the overall prevalence of $49.6 \%$ in India. ${ }^{27}$

There is no single test that takes into consideration all the factors and which can precisely anticipate an individual's vulnerability to dental caries. The risk of dental caries can be evaluated by analyzing and integrating several causative factors. The use of multivariate analysis combining several factors offers the potential of making relatively good predictions with reasonable sensitivity and specificity. Besides this, it also provides knowledge of the relationships and strengths among the variables. The present study showed that children with higher levels of MS in saliva were five times more likely to get ECC. Similarly, a child with a positive history of bottle feeding at night is 17 times more prone to developing ECC, and the presence of hypoplasia also predisposes a child 10 times to have ECC.

The study has a few limitations. Firstly, a face-to-face interview would lead to the interviewer's bias or social desirability bias. However, it was preferred over a self-administered questionnaire since it eliminates respondent literacy, allows probing for additional information, assured completeness of the questionnaire, and increased participation of the mothers by personal contact with the investigators. Another limitation could be the lack of a control population in the present study.

\section{Conclusion and Recommendations}

Children with enamel hypoplasia, sleeping with a bottle in their mouth at night, and having high levels of MS are more vulnerable to dental caries development. Overall, the study has revealed important risk factors that can be utilized to prepare a risk assessment tool for the pediatric population in India. Being a prospective study, the findings of the present study provides detailed insight into the risk factors of ECC and has practical implications. Implementing a dental component during pregnancy and initial years of life could have fruitful repercussions in reducing the burden of oral diseases. This window of opportunity can be utilized through policy at national levels.

The pediatricians might be aware of many aspects of oral health still there are certain causative factors that have been underlooked by them and there is a need for timely referral of children with unmet dental needs to a dentist by pediatricians.

Table 1: Gender predilection in children at baseline

\begin{tabular}{|c|c|c|c|c|}
\hline \multirow[b]{2}{*}{ Gender } & & \multicolumn{2}{|c|}{ Caries } & \multirow[b]{2}{*}{ Total } \\
\hline & & Absent & Present & \\
\hline \multirow{2}{*}{ Female } & Number & 30 & 6 & 36 \\
\hline & Percentage & $39 \%$ & $33.3 \%$ & $37.9 \%$ \\
\hline \multirow{2}{*}{ Male } & Number & 47 & 12 & 59 \\
\hline & Percentage & $61 \%$ & $66.7 \%$ & $62.1 \%$ \\
\hline Total & Number & 77 & 18 & 95 \\
\hline
\end{tabular}


Risk Factors of Early Childhood Caries

Table 2: Comparative evaluation of various risk factors associated with the development of early childhood caries

\begin{tabular}{|c|c|c|c|c|c|c|}
\hline Risk factors & & Caries absent & Caries present & Total & $X 2$ & $p$-value \\
\hline \multirow{5}{*}{$\begin{array}{l}\text { Age at which bottle } \\
\text { feeding was started }\end{array}$} & $0-3$ months & $38(49.4 \%)$ & $2(11.1 \%)$ & $40(42.1 \%)$ & 12.491 & $<0.05^{*}$ \\
\hline & $3-6$ months & $16(20.8 \%)$ & $8(44.4 \%)$ & $24(25.3 \%)$ & & \\
\hline & 6-9 months & $11(14.3 \%)$ & $6(33.3 \%)$ & $17(17.9 \%)$ & & \\
\hline & 9-12 months & $7(9.1 \%)$ & $2(11.1 \%)$ & $9(9.5 \%)$ & & \\
\hline & After 12 months & $0(0 \%)$ & $0(0 \%)$ & $0(0 \%)$ & & \\
\hline \multirow{3}{*}{$\begin{array}{l}\text { Bottle feeding at } \\
\text { night }\end{array}$} & Never bottle fed & $38(49.4 \%)$ & $2(11.1 \%)$ & $40(42.1 \%)$ & 17.382 & $<0.0001^{* *}$ \\
\hline & No night bottle feeding & $16(20.8 \%)$ & $1(5.65)$ & $17(17.9 \%)$ & & \\
\hline & Night bottle feeding & $23(29.9 \%)$ & $15(83.35)$ & $38(40 \%)$ & & \\
\hline \multirow[t]{4}{*}{$\begin{array}{l}\text { Pattern of bottle } \\
\text { feeding at night }\end{array}$} & $\begin{array}{l}\text { Never bottle fed and no history of } \\
\text { night feeding }\end{array}$ & $54(70.1 \%)$ & $3(16.7 \%)$ & $57(60 \%)$ & 38.110 & $<0.0001^{* * *}$ \\
\hline & Child slept with bottle in mouth & $6(7.8 \%)$ & $13(72.2 \%)$ & $19(20 \%)$ & & \\
\hline & Bottle was withdrawn before sleeping & $17(22.1 \%)$ & $2(11.1 \%)$ & $19(20 \%)$ & & \\
\hline & Fed with bottle whenever demanded & $0(0 \%)$ & $0(0 \%)$ & $0(0 \%)$ & & \\
\hline \multirow[t]{9}{*}{ Content of bottle } & Never used bottle & $38(49.4 \%)$ & $2(11.1 \%)$ & $40(42.1 \%)$ & 10.162 & $<0.05^{*}$ \\
\hline & Plain milk & $5(6.5 \%)$ & $1(5.6 \%)$ & $6(6.3 \%)$ & & \\
\hline & Milk with sugar and additive & $10(13 \%)$ & $6(33.3 \%)$ & $16(16.8 \%)$ & & \\
\hline & Milk with sugar & $24(31.2 \%)$ & $9(50 \%)$ & $33(34.7 \%)$ & & \\
\hline & Occasionally & $6(7.8 \%)$ & $2(11.1 \%)$ & $8(8.4 \%)$ & & \\
\hline & Only when needed & $0(0 \%)$ & $0(0 \%)$ & $0(0 \%)$ & & \\
\hline & Once a year & $0(0 \%)$ & $0(0 \%)$ & $0(0 \%)$ & & \\
\hline & Every 6 months & $1(1.3 \%)$ & $0(0 \%)$ & $1(1.1 \%)$ & & \\
\hline & When first tooth erupted & $0(0 \%)$ & $0(0 \%)$ & $0(0 \%)$ & & \\
\hline \multirow{7}{*}{$\begin{array}{l}\text { Oral hygiene } \\
\text { measures }\end{array}$} & Does not clean & $62(80.5 \%)$ & $10(55.6 \%)$ & $72(75.8 \%)$ & 10.140 & $<0.05^{*}$ \\
\hline & Brush with paste & $12(15.6 \%)$ & 7 (38.9\%) & $19(20 \%)$ & & \\
\hline & Brush with tooth powder & $0(0 \%)$ & $0(0 \%)$ & $0(0 \%)$ & & \\
\hline & Brush alone dipped in water & $0(0 \%)$ & $0(0 \%)$ & $0(0 \%)$ & & \\
\hline & Finger with paste & $3(3.9 \%)$ & $0(0 \%)$ & $3(3.2 \%)$ & & \\
\hline & Finger with powder & $0(0 \%)$ & $0(0 \%)$ & $0(0 \%)$ & & \\
\hline & Other methods & $0(0 \%)$ & $1(5.6 \%)$ & $1(1.1 \%)$ & & \\
\hline \multirow{5}{*}{$\begin{array}{l}\text { Assistance provided } \\
\text { to children for } \\
\text { cleaning }\end{array}$} & Never & $62(80.5 \%)$ & $10(55.6 \%)$ & $72(75.8 \%)$ & 7.890 & $<0.05^{*}$ \\
\hline & Child alone & $8(10.4 \%)$ & $4(22.2 \%)$ & $12(12.6 \%)$ & & \\
\hline & Parents alone & $7(9.1 \%)$ & $3(16.7 \%)$ & $10(10.5 \%)$ & & \\
\hline & Both child and parents & $0(0 \%)$ & $1(5.6 \%)$ & $1(1.1 \%)$ & & \\
\hline & Child under supervision & $0(0 \%)$ & $0(0 \%)$ & $0(0 \%)$ & & \\
\hline \multirow{3}{*}{$\begin{array}{l}\text { Frequency of tooth } \\
\text { paste usage }\end{array}$} & No toothpaste used with brush & $65(84.4 \%)$ & $11(61.1 \%)$ & $76(80 \%)$ & 4.952 & $<0.05^{*}$ \\
\hline & Fluoridated paste once a day & $11(14.2 \%)$ & $6(33.3 \%)$ & $17(17.9 \%)$ & & \\
\hline & Non fluoridated paste once a day & $1(1.2 \%)$ & $1(5.5 \%)$ & $2(2.1 \%)$ & & \\
\hline \multirow[t]{4}{*}{ Caries activity test } & Moderate caries activity & $3(3.9 \%)$ & $7(38.9 \%)$ & $10(10.5 \%)$ & 19.34 & $<0.001^{* *}$ \\
\hline & Mild caries activity & $11(14.3 \%)$ & $2(11.1 \%)$ & $13(13.7 \%)$ & & \\
\hline & Very mild caries activity & $29(37.7 \%)$ & $4(22.2 \%)$ & $33(34.7 \%)$ & & \\
\hline & No caries activity & $34(44.2 \%)$ & $5(27.8 \%)$ & 39 (41.1\%) & & \\
\hline \multirow[t]{4}{*}{ S. mutans levels } & $<10^{4} \mathrm{CFU} / \mathrm{mL}$ (score 0) & $64(83.1 \%)$ & $7(38.9 \%)$ & $71(74.7 \%)$ & 21.762 & $<0.001^{* *}$ \\
\hline & $<10^{5} \mathrm{CFU} / \mathrm{mL}$ (score 1$)$ & $11(14.3 \%)$ & $5(27.8 \%)$ & $16(16.8 \%)$ & & \\
\hline & $10^{5}-10^{6}($ score 2$)$ & $2(2.6 \%)$ & $6(33.3 \%)$ & $8(8.4 \%)$ & & \\
\hline & $>10^{6} \mathrm{CFU} / \mathrm{mL}$ (score 3 ) & $0(0 \%)$ & $0(0 \%)$ & $0(0 \%)$ & & \\
\hline \multirow[t]{2}{*}{ Hypoplasia } & Absent & $74(96.1 \%)$ & $9(50 \%)$ & $83(87.4 \%)$ & 28.100 & $<0.0001^{* * *}$ \\
\hline & Present & $3(3.9 \%)$ & $9(50 \%)$ & $12(12.6 \%)$ & & \\
\hline \multirow[t]{2}{*}{ Baseline caries status } & $\begin{array}{l}\text { Caries absent at baseline } \\
\text { (12-18 months) }\end{array}$ & $77(100 \%)$ & $2(11.2 \%)$ & $79(83.1 \%)$ & 82.307 & $<0.001^{* * *}$ \\
\hline & Caries present at baseline recording & $0(0 \%)$ & 16 (88.8\%) & $16(16.8 \%)$ & & \\
\hline
\end{tabular}

${ }^{*}$ A result is statistically significant if $p<0.05, * *$ is highly significant if $p<0.01,{ }^{* * *}$ is very highly significant if $p<0.001$, and is not significant if $p>0.05$ 
Table 3: Logistic Regression for determining risk factors that had a significant bearing on development of early childhood caries

\begin{tabular}{|c|c|c|c|c|c|c|c|c|}
\hline \multirow[b]{2}{*}{ Step $1 a$} & \multirow[b]{2}{*}{$b$} & \multirow[b]{2}{*}{ S.E. } & \multirow[b]{2}{*}{ Wald $^{a}$} & \multirow[b]{2}{*}{$d f$} & \multirow[b]{2}{*}{ Sig. } & \multirow[b]{2}{*}{$\operatorname{Exp}(B)^{b}$} & \multicolumn{2}{|c|}{ 95\% Cl. for $\operatorname{EXP}(B)$} \\
\hline & & & & & & & Lower & Upper \\
\hline History of bottle feeding at night & 2.876 & 1.172 & 6.020 & 1 & 0.014 & 17.747 & 1.784 & 176.565 \\
\hline SM levels & 1.694 & 0.815 & 4.315 & 1 & 0.038 & 5.439 & 1.100 & 26.882 \\
\hline Caries activity test & -0.717 & 0.545 & 1.732 & 1 & 0.188 & 0.488 & 0.168 & 1.421 \\
\hline History of breast feeding at night & -0.103 & 0.939 & 0.012 & 1 & 0.913 & 0.902 & 0.143 & 5.683 \\
\hline Pattern of bottle feeding at night & -1.148 & 0.929 & 1.529 & 1 & 0.216 & 0.317 & 0.051 & 1.958 \\
\hline Presence of hypoplasia & 2.304 & 1.149 & 4.020 & 1 & 0.045 & 10.019 & 1.053 & 95.325 \\
\hline Time of consumption of candy and toffees & -0.792 & 1.110 & 0.510 & 1 & 0.475 & 0.453 & 0.051 & 3.986 \\
\hline Mother's working status & 1.386 & 1.163 & 1.419 & 1 & 0.234 & 3.999 & 0.409 & 39.098 \\
\hline Mother's education & 0.138 & 0.559 & 0.061 & 1 & 0.805 & 1.148 & 0.384 & 3.431 \\
\hline Parents visit to dental with child & 0.222 & 0.755 & 0.086 & 1 & 0.769 & 1.248 & 0.284 & 5.487 \\
\hline History of use of sugar based medicaments & 0.691 & 0.811 & 0.726 & 1 & 0.394 & 1.996 & 0.407 & 9.790 \\
\hline Constant & -6.097 & 4.288 & 2.022 & 1 & 0.155 & 0 & 0.002 & \\
\hline
\end{tabular}

a, constant of logistic regression analysis; $b$, odd ratio that determines the strength of the correlation

\section{References}

1. Ramos-Gomez JF, Tomar SL, Ellison J, et al. Assessment of early childhood caries and dietary habits in a population of migrant Hispanic children in Stockton California. ASDC J Dent Child 1999;66(6):395-403. PMID: 10656122

2. Ripa LW. Nursing caries: a comprehensive review. Pediatr Dent 1988;10(4):268-282. PMID: 3078603.

3. Kaste LM, Gift HC. In appropriate infant bottle feeding, status of the healthy people 2000 objective. Arch Pediatr Adolesc Med 1995;149(7):786-791. DOI: 10.1001/archpedi.1995.02170200076012

4. Ismail Al, Sohn W. A systematic review of clinical diagnostic criteria of early childhood caries. J Public Health Dent 1999;59(3):171-188. DOI: 10.1111/j.1752-7325.1999.tb03267.x

5. Department of Health. Comprehensive Dental Health Program 1993-1998. Manila: Government of the Philippines; 1992.

6. Carino KMG, Shinada K, Kawaguchi Y. Early childhood caries in northern Philippines. Community Dent Oral Epidemiol 2003;31(2): 81-89. DOI: 10.1034/j.1600-0528.2003.00010.x

7. Koch G. Effect of sodium fluoride in dentifrice and mouthwash on incidence of dental caries in school children. Odontol Revy 1967;18:72-76.

8. Ainamo J, Bay I. Problems and proposals for recording gingivitis and plaque. Int Dent J 1975;25(4):229-235. PMID: 1058834.

9. Grainger RM, Jarrett M, HoneySwab test for dental caries activity: an epidemiological study SL. J Can Dent Assoc 1965;31:515-526. PMID: 14338416.

10. Grainger RM, Nikiforuk G. Determination of relative caries experienceG. J Can Dent Assoc 1960;26:531.

11. Jensen $B$, Bratthall D. A new method for the estimation of mutans streptococci in human saliva J Dent Res 1989;68(3):468-471. DOI: 10.1177/00220345890680030601

12. Bowen WH. Caries activity tests. Int Den J 1969;19:267-272. PMID: 4892618.

13. M Grindefjord, Dahllof G, B Nilsson, et al. Stepwise prediction of dental caries in children up to 3.5 years of age. Caries Res 1996;30(4):256-266. DOI: 10.1159/000262333

14. Reisine ST, Psoter W. Socioeconomic status and selected behavioral determinants as risk factors for dental caries. J Dent Educ 2001;65(10):1009-1016. PMID: 11699971.

15. Granath $L$, Cleaton Jones $P$, Fatti $P$, et al. Correlations between caries prevalence and potential etiologic factors in large samples of 4-5 years old children. Community Dent Oral Epidemiol 1991;19(5): 257-260. DOI: 10.1111/j.1600-0528.1991.tb00162.x

16. Holbrook WP, Desoet JJ, DeGraaff J. Prediction of dental caries in pre-school children. Caries Res 1993;27(5):424-430. DOI: 10.1159/000261574

17. Grinderfjord M, Dahllof G, Ekstrom G, et al. Caries prevalence in 2.5-year-old children. Caries Res1993;27(6):505-510. DOI: $10.1159 / 000261589$

18. Abernathy DD. et al. Dental knowledge, attitudes and behavior among Kuwaiti mothers and school teachers. J Pedodont 1997:56:1236-1247.

19. Casamassimo PS, Thikkurissy S, Edelstein BL, et al. Beyond the dmft: the human and economic cost of early childhood caries. J Am Dent Assoc 2009;140(6):650-657. DOI: 10.14219/jada.archive.2009.0250

20. Jain M, Namdev R, Bodh M, et al. Social and behavioral determinants for early childhood caries among preschool children in India. J Dent Res Dent Clin Dent Prospects 2015;9(2):115-120. DOI: 10.15171/ joddd. 2014.023

21. Toutouni H, Nokhostin MR, Amaechi BT, et al. The prevalence of early childhood caries among 24 to 36 -month-old children of Iran: using the novel ICDAS-II method. J Dent(Shiraz) 2015;16(4):362-370. PMID: 26636126.

22. Twetman S, Boustedt K, Roswall J, et al. Systematic review suggests a relationship between moderate to late preterm birth and early childhood caries. Acta Paediatr 2020;109(12):2472-2478. DOI: 10.1111/apa.15424

23. Shi L, Jia J, Li C, et al. Relationship between preterm, low birth weight and early childhood caries: a meta-analysis of the case-control and cross-sectional study. Biosci Rep 2020;40(8):BSR20200870. DOI: 10.1042/BSR20200870

24. Moynihan P, Tanner LM, Holmes RD, et al. Systematic review of evidence pertaining to factors that modify risk of early childhood caries. JDR Clin Trans Res 2019;4(3):202-216. DOI: $10.1177 / 2380084418824262$

25. Folayan MO, Alade M, Adeniyi A. et al. Association between developmental dental anomalies, early childhood caries and oral hygiene status of 3-5-year-old children in lle-Ife, Nigeria. BMC Oral Health 2019;20(1):1. DOI: 10.1186/s12903-019-0991-2

26. Policy on Early Childhood Caries (ECC): classifications, consequences, and preventive strategies. Pediatr Dent 2016;38(6):52-54.

27. Ganesh A, Muthu MS, Mohan A, et al. Prevalence of early childhood caries in India - a systematic review. Indian J Pediatr 2019;86(3): 276-286. DOI: 10.1007/s12098-018-2793-y 